\title{
The 2019 General Election and the teaching profession in England
}

\author{
Mike Coldwell* and Sam Twiselton \\ Sheffield Hallam University
}

\section{Introduction}

Academics tend to avoid words like crisis; they prefer more sober language. So when in a comprehensive analysis of teaching workforce data - Worth and Van den Brande (2019: 4) write that "the secondary school system is facing a substantial teacher supply challenge over the next decade, which requires urgent action" and, further, that the rates of retention of early career teachers "have dropped significantly between 2012 and 2018" (ibid: 4) they mean: we are facing a crisis. And figures released whilst writing this article indicate the problem is becoming more acute, as we trained too few MFL, physics, mathematics and chemistry teachers in the last year. The current teacher recruitment crisis is as much caused by the number of teachers we lose every year as it is our failure to convince enough people to join the profession. Ensuring teachers in England get a world class induction period, for example, is so important because it helps to tackle both the lack of people wanting to become teachers and how to hold onto the ones we already have. Why does this matter so much? Apart from the obvious reasons it's worth reminding ourselves why teacher retention and recruitment are vital to children - particularly the most disadvantaged. Not having enough teachers impacts most on schools with the poorest intakes. Statistics from Education Datalab show that schools with affluent intakes have double the percentage of teachers with more than ten years' experience compared to the poorest.

In this article, we consider some of the policy directions taken under the last administration - reaching back to 2010, when the Conservatives returned to power in coalition - in the context of the teaching profession in England. We focus on a set of sometimes inconsistent policy approaches, examining how the main parties' 2019 manifestos indicate how they will, directly and indirectly, address the challenges facing teachers in schools during the course of the next parliament.

\section{The teaching profession: key policy areas}

Teachers' pay has fallen, like the rest of the public sector facing austerity measures since 2010 , by around $10-12$ per cent in real terms. It is arguable the extent to which this is a decisive factor in recruitment and retention, except possibly in relation to STEM subjects in secondary school especially in the early career of teachers, although the case has been made as this commentary was being written that pay is crucial. All three major parties in England focus on this area, with both the Conservatives and Lib 
Dems promising increased starting salaries, with Labour promising a more thorough overhaul of teacher pay.

More directly influential, it appears from a number of analyses, is that teacher workload (combined with stress) is a key problem. The Conservative administrations from 2015 onwards have put in place a range of policies aiming to address this, with some success in reducing reported hours worked (Walker et al, 2019), particularly guidance on planning, marking, and data. Nevertheless, the most recent governmentcommissioned teacher workload survey (Walker et al, 2019) found that 70 per cent of primary teachers and over 80 per cent of secondary teachers state that workload is a fairly or very serious problem. Walker et al (2019: 12) put this starkly: "most respondents reported that they could not complete their workload within their contracted hours, that they did not have an acceptable workload, and that they did not achieve a good work-life balance." Both Labour and the Lib Dems link this to the 'high stakes culture' of inspection and testing as in need of reform, and both pledge to reform inspection and promise significant overhaul of assessment favouring teacherled testing. The Conservatives see no need for reform here, focussing on measures related to pupil behaviour (including supporting school discipline policies and supporting headteachers in exclusion).

The teacher shortage issue (affecting, in particular, secondary Physics and Mathematics teachers) has been addressed alongside a range of other measures as part of the outgoing Conservative administrations ambitious and wide ranging Teacher Recruitment and Retention Strategy. It includes proposals that address leadership, culture, workload, flexible working, accountability and - most strikingly (and importantly) - early career support and development. This early career teacher focus included extending the induction period, providing an evidence informed framework which sets out an entitlement to support, time off timetable to do it, with time and support also for teacher educators - all funded. This is a potentially important policy move. A key finding from the Carter Review of Initial Teacher Training (ITT) was that ITT is too short and the report recommended that it therefore needed to be joined up to ongoing early career support and development. The Early Career Framework (ECF) and the recently published ITT Framework between them represent a minimum entitlement of at least three years early career support and development, bringing the English system nearer to high performing education systems elsewhere. Equally if not more significant, the ECF recognises the central importance of high quality, well trained mentors. We know this to be one of the 'make or break' things in ITE and the same is/will be true in the early career phase. Again, get this right and the support, reflection and relationships needed for a novice teacher to feel valued and really able to flourish will be in place.

There is no mention of the Early Careers Framework in the Conservative manifesto, however, and we are not clear whether this will be implemented beyond the current pilot phase under a majority Conservative government. Labour and the Lib Dems do explicitly address teacher supply, in an area of continuity with aspects of current policy. Labour's new 'teacher supply service' aims to replace private supply agencies, and Lib Dems promise to train 20,000 new teachers. The Lib Dems ally this with an entitlement to 50 hours per year fully funded CPD.

\section{Oversight of schools}

The set of policies discussed above intersects with many other areas of education, but in the interests of space we focus on just one. Since 2010, we have seen an acceleration of increases in schools outside of local government control, and the creation of new schools as academies and free schools. Now, the large majority of 
secondary schools and a growing minority of primary schools are outside LA supervision. Media coverage has been preoccupied with Free Schools, which are both small in number (around 500) and often fail to reach the areas of greatest need and the families within them (see Mills, Hunt and Andrews, 2019), with some high profile notable and interesting exceptions, of course. But in the context of a state schools system of some 22,000 schools, this is relatively marginal. By far the more important shift, especially since 2017, has been the explicit focus on the creation of Multiacademy trusts (MATs) as a new grouping of schools, with overarching executive leaders. Headteachers within MATs are more akin to 'area office' heads - known often as heads of school - rather than the most powerful leaders in their own right. In teacher workforce terms, this means that the MAT, as well as the school, is now the point of power: for the teacher, their primary formal accountability is to the school and the MAT. MATs are providing a new route to approaching recruitment and retention, as they recruit and provide career opportunities within a school group.

The Conservative manifesto promises more of the same in relation to school governance: there are promises to create "more good schools" and "build more free schools", but without specific numbers. In direct contrast with the Conservatives, the Labour manifesto promises to create a position where all state-funded schools have greater Local Authority oversight, with elected governance, and the Lib Dems' position is similar. In this regard, there are diametrically opposed policy positions between the Tories and the other two main parties in England. Whilst the Labour manifesto is correct in stating there is no evidence that academies and free schools perform better than those under LA oversight, it is equally the case that there is no evidence that a different form of organisational responsibility will lead to stronger performance. This is, then, a matter of ideological perspective, rooted in Labour's wish to bring in clearer democratic oversight, on the one hand, against the market-orientated preferences of the Conservatives.

Reaching back in time for a moment, this Labour manifesto position provides a potentially significant break with a deliberate policy lever implemented by successive governments since (at least) 1992, in line with what was referred to as the New Managerialism (Exworthy, 1998). From this perspective, commitment to the profession and professional body, independent from government, has been side-lined by focussing on the organisation. Government can influence organisational behaviour both by this direct freeing of schools from local control (as with the Academies programme) and by a range of accountability measures. These measures include inspection and the assessment system, both of which would be subject to reform under Lib Dem and Labour manifesto commitments (with inspection another area of clear blue water between the Conservatives - recently suggesting increasing the length of inspections and the other two main parties in England, looking to replace Ofsted with a different body altogether).

\section{Summary and conclusion}

In summary, in relation to the areas discussed in this piece at least, there is much in common between the Labour and Lib Dems positions, and either clear differences with, or a lack of discussion in, the Conservative manifesto. Overall, it is in their differing positions on the organisation of schooling - with continued differentiation (or fragmentation) under the Conservative position, against greater local accountability (or homogenisation) under the other main parties in England - where there is some of the strongest difference. Further, whilst the Tories seem content to support the continued strong role of testing and inspection, this is subject to significant reform under the 
other parties. And Labour and Lib Dems present a more wide ranging, coherent (both internally and between the two) set of proposals that focus on teacher quality, recruitment and retention.

Finally, there have been interesting, and related, counterbalances to the organisational focus on the school emerging during the last two parliaments. Firstly, the creation of a new professional body for teachers, the Chartered College of Teaching (CCOT), has been partly funded and supported by the last government: it has recently announced full independence from March 2020, which will be of interest to any new administration facing what may become a powerful and independent voice. Secondly, again explicitly supported by government since 2010, there has been a major shift in the development and use of research evidence. The Education Endowment Foundation (EEF) and other groups such as ResearchEd have shifted the landscape. However, there are few cast iron examples of this making significant inroads into school practices: exceptions, perhaps, including the use of EEF Guidance Reports and increasing interest, pushed by recent Ofsted publications, in applications of cognitive science. Whilst the CCOT is moving outside government control, EEF appears to be moving more in line with it by contributing to new government policy agendas. CCOT launched its own 'Teachers' Manifesto' with detailed recommendations in four areas:

1. Improved quality of teacher CPD.

2. Improved teacher job satisfaction.

3. The teaching profession is research-informed.

4. Establish career-pathways focused on classroom.

These areas dovetail with many of the issues identified above, and are explicitly discussed in the Labour and Lib Dem manifestos; yet they are largely absent (with the exception of 2 , in so far as this is related to pupil behaviour) in the pared back Tory manifesto.

But, arguably, missing from all the main parties' positions and inherent in the CCOT document is a clear focus on teacher voice, and teacher agency. Whatever is written in the manifestos, this will be an important and ongoing area of debate during the next parliament.

* Correspondence address: Professor Mike Coldwell, Centre for Development and Research in Education (CDARE), Sheffield Institute of Education (SloE), Arundel Building, City Campus, Sheffield Hallam University, Howard Street, Sheffield, S1 1WB. Email: $\underline{\text { m.r.coldwell@shu.ac.uk }}$

\section{References}

Exworthy, M. (Ed.) (1998) Professionals and the New Managerialism. McGraw-Hill Education (UK).

Mills, B., Hunt, E. and Andrews, J. (2019) Free Schools in England: 2019 Report. Available at: https://epi.org.uk/wp-content/uploads/2019/10/Free-schools-inEngland-2019 EPI.pdf

Walker, M., Worth, J. and Van den Brande, J. (2019) Teacher workload survey 2019: Research report. London: Department for Education.

Worth, J. and Van den Brande, J. (2019) Teacher Labour Market in England: Annual Report 2019. Slough: NFER. ISBN 978-1-911039-87-7. 